\title{
PENGARUH KECEPATAN SUDUT TERHADAP EFISIENSI POMPA SENTRIFUGAL JENIS TUNGGAL
}

\author{
Mustakim \\ Jurusan Teknik Mekanika Politeknik Teknologi Kimia Industri (PTKI) Medan \\ Jl. Medan Tenggara VII, Medan \\ mustakim ok@yahoo.com
}

\begin{abstract}
Abstrak
Unjuk kerja pompa sentrifugal banyak dipengaruhi oleh disain impeller, rumah pompa, laju aliran dan kecepatan sudut. Efisiensi merupakan hal yang sangat penting pada penggunaan pompa sentrifugal karna berkaitan dengan energi yang dipakai untuk menggerakan sistem, dari hal tersebut peneliti ingin mengetahui pengaruh kecepatan sudut terhadap pompa sentrifugal jenis tunggal. Metode yang digunakan pada penelitian ini adalah eksperimen. Pada penelitian ini digunakan pompa sentrifugal dengan motor 1 phase 220 volt dan head hisap $20,1 \mathrm{~m}$. Untuk pengukuran tekanaan suction dan discharge digunakan pressure gauge jenis bourdon, untuk varisai kecepatan sudut digunakan inverter, sedangkan untuk pengukuran debit aliran digunakan flow meter dan fluida yang dipakai adalah air. Variasi kecepatan sudut yang digunakan $999 \mathrm{rad} / \mathrm{s}$ sampai $3000 \mathrm{rad} / \mathrm{s}$. Jika kecepatan sudut pompa bertambah maka debit aliran akan meningkat, ini sebabkan karna putaran poros pompa yang memutar impeller berputar semangkin tingggi sehingga air yang dipindahkan semakin banyak. Penambahan kecepatan sudut berbanding lurus terhadap kenaikan debit aliran, Semakin bertambah kecepatan sudut pompa maka head pompa akan semakin meningkat, ini disebabkan karna bertambahnya debit fluida yang mengalir yang mengakibatkan tekanan pada sisi discharge pompa semakin meningkat. Pada kecepatan sudut $3000 \mathrm{rad} / \mathrm{s}$ pompa dapat menghasilkan head hingga $12,28249744 \mathrm{~m}$, Semakin bertambah kecepatan sudut maka efisiensinya semakin meningkat, ini disebabkan karena daya hidrolik pompa semakin meningkat dimana peningkatan daya hidrolik disebabkan karna kapasitas debit aliran yang bertambah dan head pompa yang semakin meningkat
\end{abstract}

Kata kunci: Pompa sentrifugal, Kecepatan Sudut, Efisiensi pompa.

\section{PENDAHULUAN}

\section{Latar Belakang}

Pompa adalah peralatan mekanis yang mengubah kerja mekanis poros menjadi energi mekanis fluida dan energi yang diterima oleh fluida ini digunakan untuk menaikkan tekanan dari fluida tersebut serta digunakan untuk melawan tahanan yang terdapat pada saluran sehingga dapat dikatakan fungsi dari pompa adalah untuk memindahkan fluida dari suatu tempat ke tempat lain dengan cara manaikkan tekanan fluida tersebut. Pada umumnya pompa digunakan untuk menaikkan fluida dari satu tempat yang rendah ke tempat yang lebih tinggi atau digunakan untuk mengalirkan fluida dari suatu tingkat tertentu ke suatu tempat dengan menggunakan pipa yang sangat panjang. Pompa sentrifugal banyak digunakan di dunia industri seperti pada Water chiller, Perminyakan, Perusahaan Daerah Air Minum ( PDAM ), industri kimia dan lainnya . Unjuk kerja pompa sentrifugal banyak dipengaruhi oleh disain impeller, rumah pompa, laju aliran dan kecepatan sudut. Efisiensi merupakan hal yang sangat penting pada penggunaan pompa sentrifugal karna berkaitan dengan energi yang dipakai untuk menggerakan sistem mekaniknya, dari hal tersebut peneliti ingin mengetahui pengaruh kecepatan sudut terhadap pompa sentrifugal jenis tunggal. 


\section{Tujuan Penelitian}

Penelitian bertujuan untuk mengetahui pengaruh kecepatan sudut terhadap effisiensi pompa sentrifugal jenis tunggal.

\section{TINJAUAN PUSTAKA}

\section{Sifat - sifat Fluida}

Ada beberapa macam sifat fluida berhubungan dengan variable yang dibutuhkan. adapun sifat - sifat fluida tersebut adalah :

\section{Rapat massa ( $\rho)$}

Rapat massa didefenisikan sebagai perbandingan massa fluida persatuan volume pada tekanan dan temperature tertentu. Rapat massa pada suatu titik ditulis dalam bentuk matematis.

$\rho=\lim _{\Delta V \rightarrow 0} \frac{\Delta m}{\Delta V} \mathrm{~kg} / \mathrm{m}^{3}$

Dengan $\Delta \mathrm{m}$ adalah massa yang menempati volume $(\Delta \mathrm{V})$ apabila massa diberikan dalam kilogram maka rapat massa adalah dalam kilogram per meter kubik.

\section{Berat Jenis $(\gamma)$}

Berat jenis adalah perbandingan antara berat benda terhadap volume benda. Berat suatu benda adalah hasil kali massa dan percepatan grafitasi. Jadi berat jenis adalah :

$\gamma=\rho \cdot g\left[\frac{N}{m^{3}}\right]$

Perubahan rapat massa dan berat jenis fluida terhadap tekanan adalah sangat kecil sehingga dalam prakteknya perubahan tersebut diabaikan.

\section{Kekentalan Fluida}

Kekentalan fluida adalah sifat fluida untuk melawan tegangan geser pada waktu bergerak atau mengalir. Kekentalan ini disebabkan oleh gaya kohesi antara partikel fluida. Fluida ideal tidak mempunyai kekentalan, sedangkan fluida encer seperti sirup dan oli mempunyai kekentalan kecil.

\section{Tekanan}

Pada prinsipnya tekanan terdiri dari tekanan atmosfir, tekanan terukur dan tekanan absolute. Tekanan atmosfir disebabkan oleh berat grafitasi udara diatas permukaan bumi dan tekanan ini sulit dihitung.
Tekanan terukur atau tekanan relatif adalah tekanan yang diperoleh dari hasil pengukuran berdasarkan tekanan atmosfir. Jika tekanan yang terukur bernilai negatif, maka tekanan terukur tersebut disebut tekanan vakum.

Tekanan absolut adalah penjumlahan atau pengurangan tekanan atmosfir terhadap tekanan terukur.

\section{Klasifikasi Pompa Sentrifugal}

Pompa sentrifugal dapat digolongkan atas pompa volut dan pompa diffuser. Adapun pompa diffuser mempunyai diffuser yang dipasang mengelilingi impeller. Guna dari diffuser ini adalah untuk menurunkan kecepatan aliran yang keluar dari impeller, sehingga energi kinetik aliran dapat diubah menjadi energi tekanan secara efisien.

\section{Kecepatan spesifik}

Kecepatan spesifik didefenisikan sebagai kecepatan dalam putaran permenit pada kondisi dimana suatu impeller akan beroperasi apabila secara proporsional ukurannya diperkecil agar dapat memberikan kapasitas 1 $\mathrm{m}^{3} / \mathrm{s}$ dan head $1 \mathrm{~m}$.

Harga kecepatan spesifik dapat diperoleh dengan rumus :

$$
\begin{gathered}
n_{s}=\frac{n \cdot Q^{1 / 2}}{H^{3 / 4}} \\
\text { dimana }: \mathrm{n}_{\mathrm{s}}=\text { kecepatan spesifik } \\
\mathrm{H}=\text { head } \text { total pompa } \\
\mathrm{n}=\text { putaran } \\
\mathrm{Q}=\text { kapasitas aliran }
\end{gathered}
$$

Berdasarkan kecepatan spesifik impeller dapat dibagi atas empat yaitu : radial, prancis, aliran campur dan propeller.

\section{Head Pompa}

Head pompa adalah kemampuan suatu pompa untuk memindahkan fluida dari suatu tempat ketempat lain yang berbeda ketinggian atau kemampuan pompa untuk memindahkan fluida antara dua tempat yang berbeda jaraknya. Secara mekanis head pompa dapat ditulis sebagai berikut :

$$
\mathrm{H}=\mathrm{H}_{\mathrm{d}}-\mathrm{H}_{\mathrm{s}}(\mathrm{m})
$$




\section{Daya Pompa}

Besarnya daya pompa yang dibutuhkan untuk mengalirkan fluida dapat dihitung dengan rumus sebagai berikut.

$$
\mathrm{P}=\gamma \cdot \mathrm{Q} \cdot \mathrm{H}
$$

dimana $: \gamma=$ Berat fluida persatuan volume

$$
\begin{aligned}
& \mathrm{Q}=\text { Kapasitas } \\
& \mathrm{H}=\text { Head } \text { total pompa }
\end{aligned}
$$

\section{Putaran Pompa}

Untuk mengatur putaran pompa dugunakan inverter yang berfungsi sebagai pengontrol kecepatan.

Daya Hidraulik $\left(\mathrm{N}_{\mathrm{h}}\right)$

$$
\mathrm{N}_{\mathrm{h}}=\text { p.g.Q.H ( Watt ) }
$$

Daya Pompa $\left(\mathrm{N}_{\mathrm{p}}\right)$

$$
\begin{aligned}
& \mathrm{N}_{\mathrm{p}}=\mathrm{T} . \omega \\
& \operatorname{dimana}: \mathrm{T}=\text { Torsi Dinamometer }(\mathrm{Nm}) \\
& \quad \omega=\text { kecepatan sudut }(\mathrm{rad} / \text { detik })
\end{aligned}
$$

Efisiensi pompa

$$
\eta=\frac{N_{h}}{N_{p}} \times 100 \%
$$

\section{METODOLOGI PENELITIAN}

Metode yang digunakan pada penelitian ini adalah eksperimen. Susunan alat percobaan yang digunakan pada eksperimen terlihat pada gambar 1. Pada penelitian ini digunakan pompa sentrifugal dengan motor 1 phase 220 volt dan head hisap 20,1 m. Untuk pengukuran tekanaan suction dan discharge digunakan pressure gauge jenis bourdon, untuk varisai kecepatan sudut digunakan inverter, sedangkan untuk pengukuran debit aliran digunakan flow meter dan fluida yang dipakai adalah air. Variasi kecepatan sudut yang digunakan $999 \mathrm{rad} / \mathrm{s}$ sampai $3000 \mathrm{rad} / \mathrm{s}$.
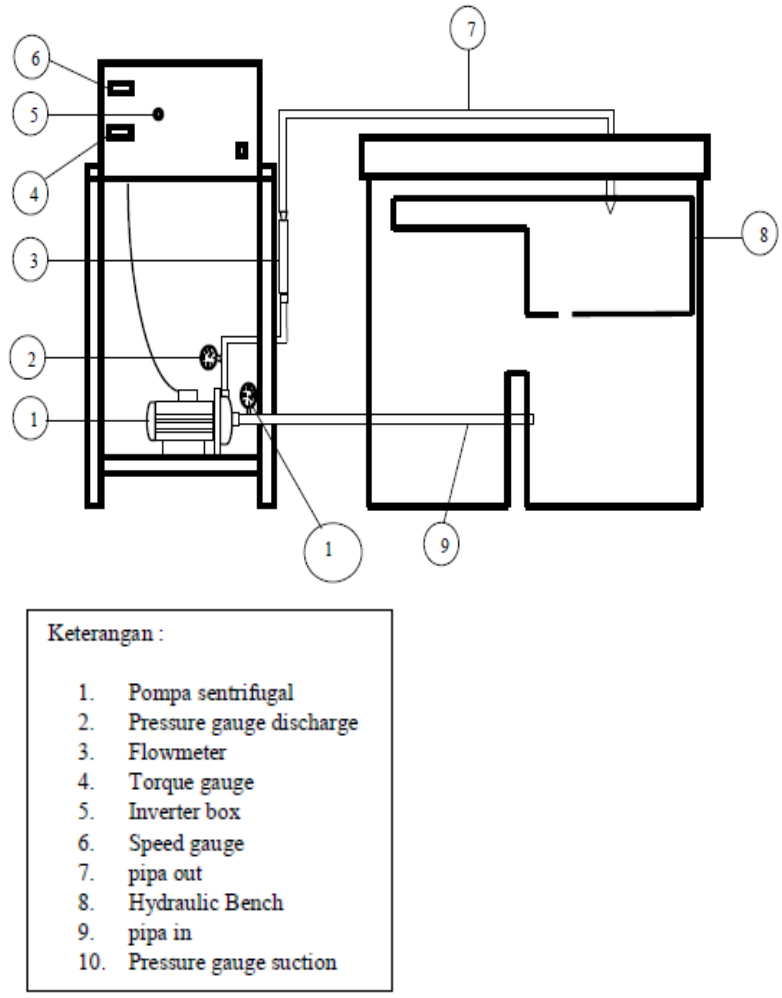

Gambar 1. Instalasi Pengujian

\section{HASIL DAN DISKUSI}

\section{Kecepatan Sudut Terhadap Debit Aliran}

Dari hasil eksperimen diperoleh jika kecepatan sudut pompa bertambah maka debit aliran akan meningkat, ini sebabkan karna putaran poros pompa yang memutar impeller berputar semangkin tingggi sehingga air yang dipindahkan semakin banyak. Seperti yang diperlihatkan pada grafik 2 pada kecepatan sudut $999 \mathrm{rad} / \mathrm{s}$ maka didapatkan debit $0,000255556 \mathrm{~m}^{3} / \mathrm{s}$ dan pada kecepatan sudut $3000 \mathrm{rad} / \mathrm{s}$ maka didapatkan debit $0,001016667 \mathrm{~m}^{3} / \mathrm{s}$. Penambahan kecepatan sudut berbanding lurus terhadap kenaikan debit aliran.

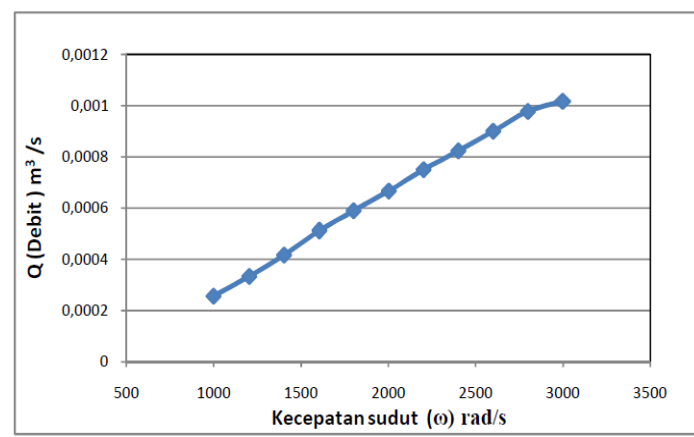

Gambar 2.Grafik pengaruh kecepatan sudut terhadap debit aliran 


\section{Kecepatan Sudut Terhadap Head Total}

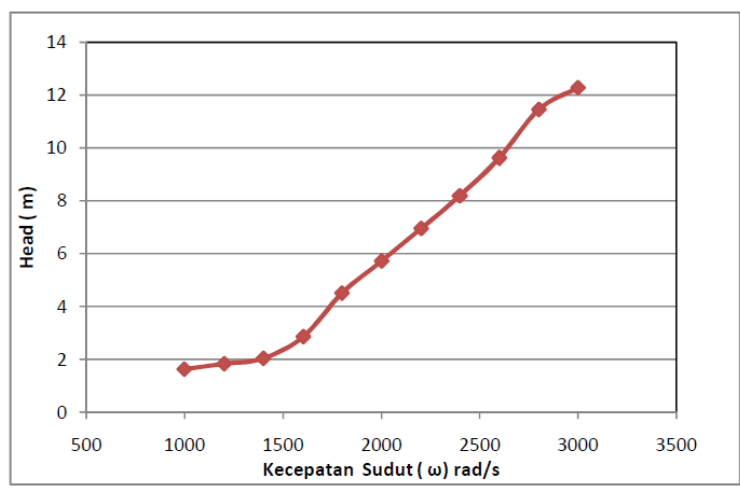

Gambar 3.Grafik pengaruh kecepatan sudut terhadap head total

Head pompa adalah kemampuan suatu pompa untuk memindahkan fluida dari suatu tempat ketempat lain yang berbeda ketinggian atau kemampuan pompa untuk memindahkan fluida antara dua tempat yang berbeda jaraknya. Head pompa di pengaruh oleh tekanan pada suction dan discharge. Dari grafik 3. Dapat dilihat bahwa semakin bertambah kecepatan sudut pompa maka head pompa akan semakin meningkat, ini disebabkan karna bertambahnya debit fluida yang mengalir yang mengakibatkan tekanan pada sisi discharge pompa semakin meningkat. Pada kecepatan sudut $3000 \mathrm{rad} / \mathrm{s}$ pompa dapat menghasilkan head hingga $12,28249744 \mathrm{~m}$.

\section{Kecepatan Sudut Terhadap Effisiensi}

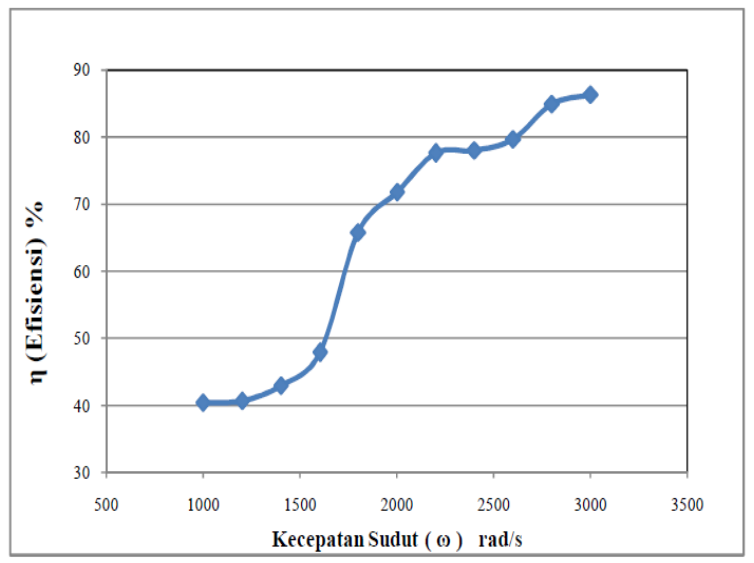

Gambar 4.Grafik pengaruh kecepatan sudut terhadap Efisiensi pompa

Efisiensi pompa sentrifugal dipengaruhi oleh nilai daya pompa dan daya hidroliknya, apabila daya hidrolik semakin besar maka nilai efisiensinya juga akan semakin meningkat. Pada gambar 4 dapat dilihat bahwa semakin bertambah kecepatan sudut maka efisiensinya semakin meningkat, ini disebabkan karena daya hidrolik pompa semakin meningkat dimana peningkatan daya hidroliknya disebabkan karna kapasitas debit aliranya yang bertambah dan head pompa yang semakin bertambah. Pada kecepatan sudut $999 \mathrm{rad} / \mathrm{s}$ efisiensi pompa hanya sampai $40,73 \%$ ini disebabakan daya pompa yang digunakan tidak sebanding dengan daya hidrolik yang di dapatkan. Sedangkan efisiensi tertinggi dapat dilihat pada kecepatan sudut $3000 \mathrm{rad} / \mathrm{s}$.

\section{KESIMPULAN}

Kesimpulan yang dapat diambil dari hasil penelitian ini adalah:

1. Jika kecepatan sudut pompa bertambah maka debit aliran akan meningkat, ini sebabkan karna putaran poros pompa yang memutar impeller berputar semangkin tingggi sehingga air yang dipindahkan semakin banyak. Penambahan kecepatan sudut berbanding lurus terhadap kenaikan debit aliran.

2. Semakin bertambah kecepatan sudut pompa maka head pompa akan semakin meningkat, ini disebabkan karna bertambahnya debit fluida yang mengalir yang mengakibatkan tekanan pada sisi discharge pompa semakin meningkat. Pada kecepatan sudut $3000 \mathrm{rad} / \mathrm{s}$ pompa dapat menghasilkan head hingga $12,28249744 \mathrm{~m}$

3. Semakin bertambah kecepatan sudut maka efisiensinya semakin meningkat, ini disebabkan karena daya hidrolik pompa semakin meningkat dimana peningkatan daya hidrolika disebabkan karna kapasitas debit aliran yang bertambah dan head pompa yang semakin bertambah.

\section{DAFTAR PUSTAKA}

[1] R.S Khurmi.,J.K Gupta (1980) Aext Book of machine Design. Eurasia publishing House LTD ram nagar, New Delhi

[2] Church.H.A ( 1980 ) Centrifugal Pump and Blower. Jhon Willey and Sons, New York. 
[3] Frank M. White. ( 1986 ) Mekanika Zat Cair. Erlangga, Jakarta.

[4] Ditzel Fritz (1988) Turbin dan

Kompresor. Erlangga, Jakarta.

[5] Daugherty.,Frazini ( 1989 ) Fluid

Mechanic with Engineering

Aplications, SI Metric Ed. MC GrawHill Book Company, Singapura.

[6] Munson Bruce.R.,Donald

[7] F.Young.,Okiishi Theodore H. (2004)

Mekanika Fluida. Erlangga, Jakarta. 